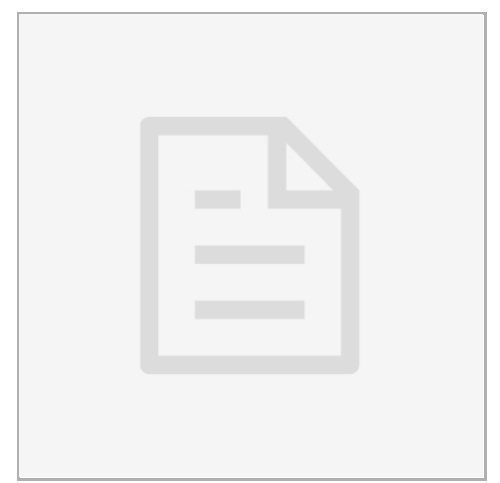

APR 10, 2020

\title{
(3) Protocols for predicting Sphagnum bogs distributional pattern in China
}

\section{c] PLOS One}

\section{Mingyang Cong ${ }^{1}$}

${ }^{1}$ Analytical \& Testing center

Mingyang Cong

Analytical \& Testing center, Jiangxi Provincial Key Lab of P...

\section{open ठaccess}

\section{DOI:}

dx.doi.org/10.17504/protocol s.io.bbtxinpn

\section{External link:}

https://doi.org/10.1371/journa l.pone.0230969

Protocol Citation: Mingyang Cong 2020. Protocols for predicting Sphagnum bogs distributional pattern in China. protocols.io

https://dx.doi.org/10.17504/p rotocols.io.bbtxinpn

\section{MANUSCRIPT CITATION:}

Cong $M$, Xu Y, Tang L, Yang $W$, Jian $M$, Predicting the dynamic distribution of bogs in China under climate change since the last interglacial period. PLoS ONE 15(4). doi: $\underline{10.1371 / \text { journal. pone.023096 }}$ $\underline{9}$

License: This is an open access protocol distributed under the terms of the Creative Commons Attribution License, which permits unrestricted use, distribution, and reproduction in any medium, provided the original author and source are credited

Protocol status: Working

Created: Jan 27, 2020 


\section{PROTOCOL integer ID:}

32343

1 Collect the center points of Sphagnum bogs. To collect the longitude and latitude for Sphagnum bogs' central points across China, we principally consulted Swamps in China and Marshes in China and then extracted occurrence data from the literature. For the records lacking specific geographic coordinates, we used Google Earth (https://earth.google.com/web/) to conduct toponymal geocoding.

2 Select appropriate environmental parameters. In all, nineteen bioclimatic environmental variables participated in predicting the pattern of Sphagnum bogs. The codes used above for variables.

3 Obtain historical and future climate scenarios datasets. All climate scenario data were calculated by the CCSM model (BCC-CSM1-1), which was developed by the National Center for Atmospheric Research from the WorldClim database (https://www.worldclim.org/). Next, the future climate datasets were applied to the four combined scenarios: RCP2.6-2050, RCP2.6-2070, RCP8.5-2050, and RCP8.5-2070.

4 Obtain the map vector data and software. A 1:1000000 administrative regionalization map of China was downloaded from the National Catalogue Service for Geographic Information (http://www.webmap.cn/main.do?method=index). ArcGIS10.3 was obtained from the Geographic Information System platform developed by the Environmental Systems Research Institute company in the United States. MaxEnt 3.3.3 k software was obtained from the Princeton University website (http://www.cs.princeton.edu/ schapire/maxent/).

$5 \quad$ Predicting the dynamic distribution pattern of Sphagnum bogs. The receiver operating characteristic (ROC) curve was employed to test prediction accuracy by judging the AUC (area under the ROC curve) value (0 1). After importing the distribution and environmental datasets to MaxEnt 3.3.3 k, we calculated the contribution rate of each environmental variable with a jackknife test and set the other parameters to default values. Simultaneously, we repeated operation ten times by cross-validation and then output the ASCII grid layer with the largest AUC value. Subsequently, the arithmetic results from MaxEnt were loaded into ArcGIS10.3 to carry out suitability classification and visualization and thereby generate the potential distribution of Sphagnum bogs. It was critical to choose an appropriate threshold when converting the continuous species suitability prediction results into a Boolean classification of suitable and unsuitable habitats. The sensitivity-specificity sum maximization approach was verified to be superior to other threshold division methods.

6 Calculating the shifts in the distribution area. After modeling the current suitable habitat area for Sphagnum bogs, changes in the potential distribution areas were calculated. Future climate datasets were used to carry out the modeling and forecasting for calculating future suitable habitat areas. We cross-checked future suitable habitat areas against the current distribution to 
identify regions that were (i) gains, (ii) unchange and (iii) losses. We then calculated the area of the regions identified in (i)-(iii).

7 Identify the core distributional shifts in Sphagnum bogs. We calculated the centroids of Sphagnum bogs from their historical distribution to their future distribution by using a Pythonbased SDM toolbox. The analysis concentrated the species distribution into an independent central point and created a vector file depicting the magnitude and direction of changes over time. We observed the distributional shifts by tracking the centroid changes among different SDMs.

8 Assess the key environmental factors. The operation principle of the jackknife method is to create a series of new models by using a variable or excluding a variable in turn. Then, we compared the model results to regularized training data, testing gains and differences in AUC values among the models to assess the importance of the environment variables. 